\title{
Thermovision assessment of temperature changes in selected body areas after short-wave diathermy treatment
}

\author{
Bożena Kaźmierska ${ }^{1} \cdot$ Krzysztof Andrzej Sobiech $^{1}$ (D) Ewa Demczuk - Włodarczyk ${ }^{1}$ (D) Agnieszka Chwałczyńska ${ }^{1}$ (I)
}

Received: 23 February 2021 / Accepted: 30 October 2021 / Published online: 3 December 2021

(c) The Author(s) 2021

\begin{abstract}
The aim of this study is to provide the thermal imaging assessment of local and general surface temperature changes after short-wave diathermy treatment. The study group consisted of 26 women aged 19-24. The correct functioning of the thermoregulation system was determined by means of cold pressor and orthostatic tests. The subjects underwent short-wave diathermy treatment in the area of the right knee joint, and the body's response was determined by thermovision using a ThermaCAM P640 thermal imaging camera manufactured by FLIR. Curves were recorded in a digital form (images with a resolution of $640 \times 480$ pixels) and analyzed with ThermaCAM ReporterTM software. In people with a properly functioning thermoregulation system, the short-wave diathermy treatment statistically significantly increased the body surface temperature on the posterior surface of the knee joint. On the front side, the surface temperature decreased. There were no changes in surface temperature in the other areas of the body studied. The results of thermal imaging studies confirmed the local nature of the action of short-wave diathermy. The recommendation to use a physical procedure should be preceded by an assessment of the body's thermoregulation system level of function. Reactions to the prescribed physical treatment may be different in people with a disturbed autonomic system.
\end{abstract}

Keywords Short-wave diathermy $\cdot$ Body surface temperature $\cdot$ Thermovision

\section{Introduction}

Thermotherapy is a field of physical medicine in which we introduce thermal energy into the body during physical therapy treatments [1-8]. The body's responses are systemic and organ reactions are of an adaptive nature, i.e. the occurrence of a thermoregulatory reaction connected with the regulation of blood supply, resulting in the tension of the vegetative system [9]. One of the thermotherapy treatments is shortwave diathermy (SWD). SWD is a form of electromagnetic therapy that generates oscillation of the electromagnetic field causing the movement of ions, molecule deformation and creates a vortex of electricity, producing heat at the deep tissue level. It is the second method, after ultrasound, which according to the available literature [10], generates heat, causing the expansion of blood vessels and increases the

Agnieszka Chwałczyńska

agnieszka.chwalczynska@awf.wroc.pl

1 Faculty of Physiotherapy, Wroclaw University of Health and Sport Sciences, Av. Paderewski 35, 51-612 Wroclaw, Poland metabolism in the body. Thanks to this, blood circulation becomes smooth and the treatment has a therapeutic effect. The parameters indicated for the CPT test are the increase.

In addition, short-wave diathermy therapy normalises muscle tension and improves the work of the metabolic system. Current studies confirm the effectiveness of short-wave diathermy; however, these are most often tests based on the patient's feelings, in which they are burdened with a subjective response to pain [11-15]. The subjective assessment carried out using the VAS scale or the Laitinen questionnaire is complemented using tests of the range of motion in the joints, functional tests of the patient's mobility and the risk of falling ("Timed Up and Go"-TUG test), or the assessment of the perimeters. These measurements determine the impact of SWD in the perspective of long-term activities with at least 10 treatments $[14,15]$. However, there is no assessment of the impact of a single SWD treatment on the treatment area, i.e. the assessment of changes occurring during a single treatment, which strengthened by multiple repetition, provide us with the final effects. One of the simplest, non-invasive methods of evaluating the body's response to thermotherapy is thermovision. 
Thanks to the development of modern techniques in the field of thermography and device minimization, thermography is increasingly used. For years, it has been used in construction, food industry, energy, metallurgy and, most importantly, for non-invasive diagnostics, in medicine. In medicine, thermal imaging is used primarily as a supplement to the diagnostics of X-ray examinations, ultrasound or computed tomography. The method based on the assessment of temperature differences can be used to detect inflammation, inflammation, blood flow in blood vessels, and to assess the depth and extent of burns [16-20]. For many years, the measurement of human body temperature, and in principle its anomalies, have been used in ophthalmological, laryngological, dermtological, neurological diagnostics, urology, surgery, orthopedics, gastrology, endocrinology and even oncology. Thermovision is also used in physiotherapy and cosmetology as a diagnostic and therapeutic method [3, 16-27].

In the literature on the subject, there is a growing interest in the dynamics of body surface temperature changes under the influence of various physical factors assessed by means of a thermovision map. So far, the efficiency of the autonomic nervous system has been assessed, the importance of body composition, age, sex or fitness of the subjects has been determined, and the thermal effects of physical therapy treatments or exercise have been monitored [1, 3, 4, 20-24, 28-32]. However, no data have been found that would present an analysis of the surface temperature distribution after the application of short-wave diathermy.

Thanks to the use of the thermal imaging method, it is possible to assess the thermal effect of SWD on the body surface, which has analgesic and anti-inflammatory effects and improves the functionality of individual joints.

The objective of this work was to evaluate the thermal imaging of changes in body surface temperature after shortwave diathermy treatment in the area of the knee joint.

\section{Material and methods}

The present study was carried out in accordance with the standards of the European Association of Thermology in the laboratory of the Physiotherapy Department at the University School of Physical Education in Wrocław. Prior permission number KB-446/2016 was obtained from the Bioethical Commission at Wrocław Medical University.

In accordance with the Helsinki Declaration, the respondents gave their informed written consent to participate in the research experiment. The study was performed in accordance with the CONSORT statement (Consolidated Standards of Reporting Trials) and the CONSORT FLOW DIAGRAM scheme.

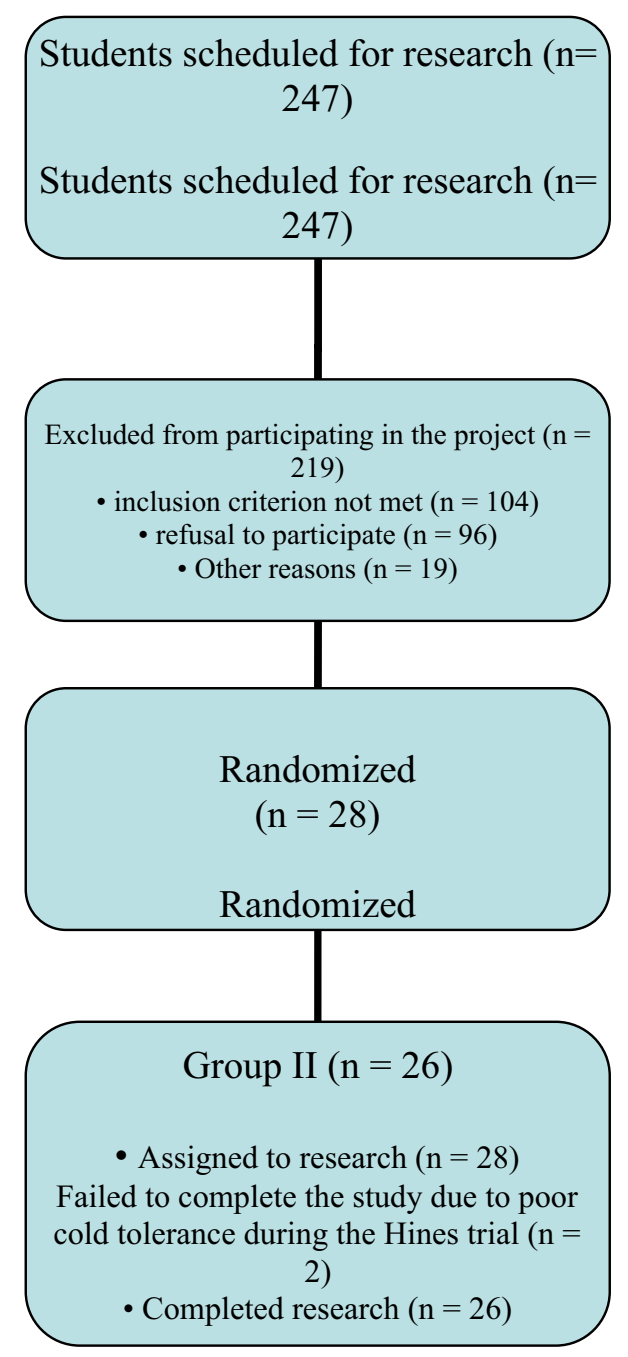

A total of 26 full-time students of the medical university were qualified to participate in the research. The study inclusion criteria were as follows: age: 19-24; female; in good health, no medical indications for physiotherapy treatment, not taking medications, with normal baseline blood pressure (120 (139)/80 (89) $\mathrm{mmHg}$ ) [33]; not consuming food or drinks containing caffeine at least $3 \mathrm{~h}$ before the test and not drinking alcohol at least $12 \mathrm{~h}$ before the test.

The exclusion criteria were: chronic diseases; feverish conditions; pregnancy or menstruation; skin lesions, wounds, scars or tattoos in the area to be examined; recent or chronic injuries of the lower limbs (i.e. fractures, dislocations); the presence of electronic implants or metal in tissues; experience of rehabilitation with the use of short-wave diathermy, smoking; left-handedness.

The mean age of the examined women was $20.5 \pm 1.4$ years, mean body height $165.0 \pm 6.2 \mathrm{~cm}$, mean body weight $59.5 \pm 8.6 \mathrm{~kg}$. Based on the obtained data, Body Mass Indices were calculated-mean value $21.9 \pm 2.9 \mathrm{~kg} \mathrm{~m}^{-2}$, BSA (Body Surface Analyzer)—mean 
value $1.58 \pm 0.14\left(\mathrm{~m}^{2}\right)$. The somatic structure of the respondents was determined using the Japanese eight-electrode body composition analyser Tanita BC-418 MA in accordance with the applicable methodology. The mean percentage of body fat (FatP) was $27.6 \pm 10.0 \%$, the mean mass of lean tissue (FFM) was $43.4 \pm 3.7 \mathrm{~kg}$, the mean total body water (TBW) was $53.4 \pm 4.5 \%$. The BMI and FatP index of the respondents indicated a normative body weight for age and gender [34].

The systolic-diastolic blood pressure (SBP/DBP) and heart rate were measured on the left arm using an Omron M10-IT automatic sphygmomanometer.

Prior to the examination, all subjects underwent acclimatisation. The research experiment consisted of two partspart I: evaluation of the function of the thermoregulation system of the subjects, part II: short-wave diathermy treatment. The selection of the treatment was based on its physical characteristics - the body's reaction to the treatment itself, especially the superficial and deep thermal reaction that occurs after the use of short-wave diathermy. At the same time, this treatment improves blood circulation, has an analgesic and anti-inflammatory effect. Before starting the research project, each of the subjects underwent the process of acclimatisation with the environment (stage 1 -duration 15 min, room temperature $22{ }^{\circ} \mathrm{C}$, humidity $45-55 \%$, sitting position, wearing a gymnastic outfit).

The function of the thermoregulation system was assessed using the Cold Pressor Test (stage 2-after a 10-min stabilisation of the heart rate in the supine position, the blood parameters were determined. Then, the CPT test was performed (10-min stabilisation in the supine position, blood parameters measurement, immersion test-duration $1 \mathrm{~min}$, water temperature $4{ }^{\circ} \mathrm{C}$, right hand-dominant, then re-measurement of parameters) and the Crampton test (stage 3 -orthostatic test, 10-min stabilisation in the lying position, measurement of blood pressure and pulse, sitting down, then after 2 min re-measurement of blood pressure and pulse). The assessment used changes in SBP, DBP and heart rate in the CPT test and Crampton Index (IC). The parameters indicated as normative for the CPT test are the increase in SBP within 10-25 mmHg, DBP remains unchanged, while in the case of IC the results are considered normal in the range of 80-94 [1, 35-39].

After evaluating the functioning of the thermoregulation system, the restitution process was carried out in all subjects (stage 4-sitting position, duration $5 \mathrm{~min}$ ).

The research experiment (part II, stage 5) consisted in performing short-wave diathermy treatment (SWD) immediately after the end of the restitution period. The SWD treatment was performed using Skanlab NG ProTM apparatus (high frequency alternating current $1 \mathrm{MHz}$, capacitor method, $300 \mathrm{~m}$ wavelength, $11 \mathrm{~m}$ short-wave diathermy), the dynamic method was used, power level 6 , treatment area$100 \mathrm{~cm}^{2}$, treatment time $-8 \mathrm{~min}$, reclining position, right lower limb bent at the hip and knee joints. The procedure was performed locally —on the anterior surface of the right knee joint with the use of small electrodes, the coupling agent was paraffin oil [40].

After each stage, the surface temperature of the anterior and posterior knee joints was measured. Temperature measurements were obtained using a ThermaCAM P640 thermal imaging camera by FLIR. Curves were recorded in a digital form (images with a resolution of $640 \times 480$ pixels, temperature range -200 to $9000{ }^{\circ} \mathrm{C}$,) and analyzed with ThermaCAM ReporterTM software [3, 4]. Research and
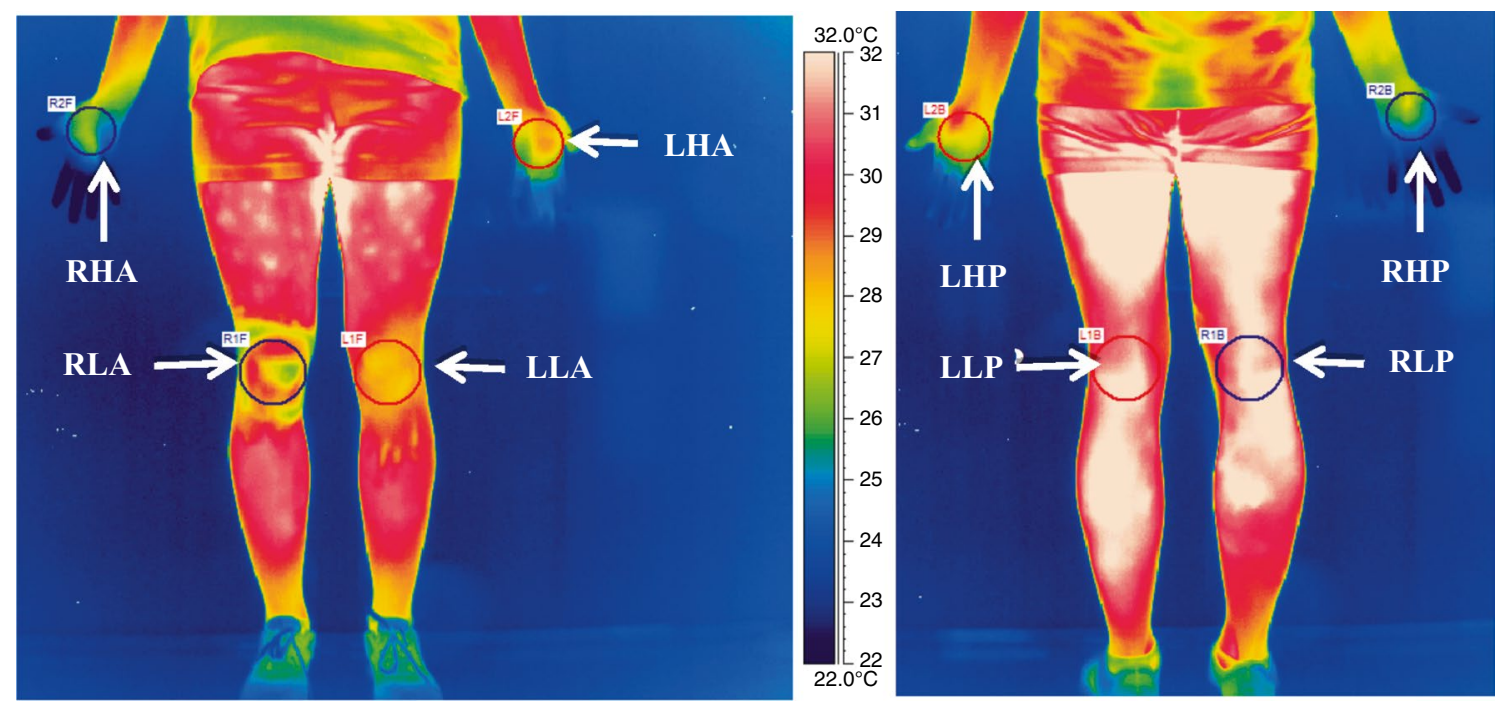

Fig. 1 Thermal imaging map of the knee joints area (anterior (A)—RLA, LLA, posteriori (P)- RLP and LLP) and hands (RHD, LHP, RHD and LHP) before the dorsal (D) and palmar treatments (P) 
procedures were carried out in the morning-10:00 to13:00 in a room with constant humidity and temperature (relative humidity $45-55 \%$, temperature $22{ }^{\circ} \mathrm{C}$ ), devoid of point heat sources. Measurements were taken at a distance of $2 \mathrm{~m}$ from the subject, in a standing position with their front and back to the camera, and with the following markings in the figures and tables: (R) —right; (L) — left (A/D) —anterior/dorsal, (P) - posteriori/palmar (Fig. 1).

The thermal imaging camera used is standardized and is only used to study the human body. The surface temperature was calculated using a program for estimating average values for a given area in accordance with the Glamorgan protocol. After thermal imaging, the treatment area was outlined by hand in Therma Researcher 2.8. Based on the contour, the average surface temperature of the selected fragment was calculated using the algorithm included in the software $[1-4,8,41,42]$.

\section{Statistical analysis}

All quantitative variables had a distribution close to normal, as verified with the Shapiro-Wilk test. The tables present these variables as mean values $(\mathrm{M})$ and standard deviations (SD). The significance of differences in mean values obtained in the tests before and after the procedure was verified by the Students' $t$-test for dependent samples. In the case of a greater number of comparisons (between individual stages), analysis of variance (ANOVA) and multiple comparisons (Tukey's post-hoc tests) were used. The test $p<0.05$ was considered a significant result. The statistical software package Statistica v. 13.3 (TIBCO, Software Inc., USA) was used for the calculations.

Table 1 Descriptive characteristics $(\mathrm{M} \pm \mathrm{SD})$ of the surface temperature $\left({ }^{\circ} \mathrm{C}\right)$ of the right anterior/posterior (RLA/P) and left anterior/posterior (LLA/P) and left hand area (dorsal/palmar LHD/P)

\section{Research results}

The subjects had the correct pulse at every stage of the experiment, which proves they had the correct heart rhythm. The average heart rate at the acclimatisation stage was $80 \pm 15$ beats/min, during the CPT test $-75 \pm 14$ beats/ min, in the Crampton 3 test $-85 \pm 13$ beats/min, and during the restitution period $-76 \pm 12$ beats $/ \mathrm{min}$. The obtained results are within the normal range for an adult. There were statistically significant differences between the heart rate values for the CPT test and the Crampton test $(p=0.010)$ and between the heart rate value for the Crampton test and restitution $(p=0.012)$. The other values do not differ statistically significantly.

The change in SBP in the CPT test in the studied women was $7 \mathrm{mmHg}$, and the IC-88.3 \pm 12.0 . The CPT results were slightly below normal and the IC was within the normal range.

The obtained results of CPT and IC prove the proper functioning of the thermoregulation system in the examined women.

Based on the thermovision assessment, the mean body temperature in the area of the knee joints and the left hand was determined after stages 1.2 . and 3. There were no statistically significant differences between the temperature values of the examined areas in individual trials, regardless of the examined side (right/left, front/back). At all stages of part I of the research experiment, the temperature of the anterior surface of the knee joint was statistically significantly lower than that of the posterior side. The results of the average surface temperature of the knee joint in stages 1,2 and 3 are presented in Table 1.

The analysis of the obtained results showed that the shortwave diathermy treatment caused a statistically significant

and comparison of the temperature between the different stages of the experiment (1st-acclimatisation. 2nd-cold pressor test. 3rdorthostatic test)

\begin{tabular}{|c|c|c|c|c|c|c|c|}
\hline \multirow[t]{2}{*}{ Examined body area } & & \multicolumn{3}{|c|}{ Experimental stage } & \multicolumn{3}{|c|}{ Post hoc $\mathrm{p}$ test results } \\
\hline & & 1 & 2 & 3 & 1. vs 2 & 1. vs 3 & 2. vs 3 \\
\hline \multirow[t]{2}{*}{ The anterior surface of the knee joint } & RLA & $28.1 \pm 1.1$ & $28.0 \pm 0.9$ & $27.9 \pm 0.8$ & 0.999 & 0.948 & 0.998 \\
\hline & LLA & $28.1 \pm 1.1$ & $28.0 \pm 0.9$ & $27.9 \pm 0.7$ & 1.000 & 0.990 & 1.000 \\
\hline Test $t$-Studenta $p$ & RLA vs LLA & 1.000 & 1.000 & 1.000 & & & \\
\hline \multirow[t]{2}{*}{ The posterior surface of the knee joint } & RLP & $30.6 \pm 1.0$ & $30.7 \pm 1.1$ & $30.5 \pm 0.7$ & 1.000 & 1.000 & 0.995 \\
\hline & LLP & $30.6 \pm 0.9$ & $30.4 \pm 1.1$ & $30.3 \pm 0.7$ & 0.937 & 0.777 & 1.000 \\
\hline Test $t$-Studenta $p$ & RLP vs LLP & 1.000 & 0.330 & 0.308 & & & \\
\hline Test $t$-Studenta $p$ & RLA vs RLP & 0.000 & 0.000 & 0.000 & & & \\
\hline Test $t$-Studenta $p$ & LLA vs LLP & 0.000 & 0.000 & 0.000 & & & \\
\hline The palmar surface of the hand & LHD & $28.6 \pm 2.1$ & $28.8 \pm 2.1$ & $27.9 \pm 2.0$ & 1.000 & 0.8793 & 0.7551 \\
\hline The dorsal surface of the hand & LHP & $28.6 \pm 2.2$ & $28.6 \pm 2.1$ & $28.1 \pm 1.9$ & 1.000 & 0.9873 & 0.9879 \\
\hline Test $t$-Studenta $p$ & & 1.000 & 0.733 & 0.713 & & & \\
\hline
\end{tabular}

Statistically significant values are marked in bold 
Table 2 Descriptive

characteristics of the surface temperature of the knee area of the right anterior/posterior (RLA/P), left anterior/posterior (LLA/P) left hand (dorsal/ palmar LHD/P) before (4) and after short-wave diathermy treatment (5). and comparison of values

\begin{tabular}{|c|c|c|c|c|}
\hline \multicolumn{2}{|l|}{ Examined body area } & \multicolumn{2}{|c|}{ Experimental stage } & \multirow{2}{*}{$\begin{array}{l}\text { Test } t \text {-Studenta } \\
p\end{array}$} \\
\hline & & 4 & 5 & \\
\hline \multirow[t]{2}{*}{ The anterior surface of the knee joint } & $\mathrm{R} 1 \mathrm{~F}$ & $28.2 \pm 0.8$ & $27.7 \pm 2.0$ & 0.212 \\
\hline & LLA & $28.3 \pm 0.7$ & $28.3 \pm 0.9$ & 1.000 \\
\hline Test $t$-Studenta $p$ & & 0.633 & 0.169 & \\
\hline \multirow[t]{2}{*}{ The back surface of the knee joint } & RLP & $30.4 \pm 0.7$ & $31.2 \pm 1.0$ & 0.017 \\
\hline & LLP & $30.2 \pm 0.6$ & $30.6 \pm 1.0$ & 0.663 \\
\hline Test $t$-Studenta $p$ & & 0.274 & 0.160 & \\
\hline Test $t$-Studenta $p$ & RLAvsB & 0.000 & 0.000 & \\
\hline Test $t$-Studenta $p$ & LLAvsB & 0.000 & 0.000 & \\
\hline The palmar surface of the hand & LHD & $27.6 \pm 1.9$ & $27.8 \pm 1.9$ & 1.000 \\
\hline The dorsal surface of the hand & LHP & $27.7 \pm 1.8$ & $27.5 \pm 1.8$ & 1.000 \\
\hline Test $t$-Studenta $p$ & & 0.846 & 0.561 & \\
\hline
\end{tabular}

Statistically significant values are marked in bold increase in the body surface temperature only at the specific area of the treatment. Evidence of the lack of a systemic reaction to SWD is demonstrated in the lack of a thermal reaction in the left hand after the procedure and the lack of statistically significant differences in the surface temperature of the left non-treated knee joint.

The increase in the temperature of the posterior surface of the knee joint (right) was accompanied by a slight decrease in temperature on the anterior side, and an increase in the temperature on the posterior side of this joint. Within the remaining analysed body sections, the surface temperature did not change (Table 2).

As in the case of CPT and IC tests, statistically significant differences were observed before and after short-wave diathermy treatment between the temperature of the anterior and posterior surfaces of the knee joint.

\section{Discussion}

Physical medicine is a discipline of knowledge concerned with the medical use of naturally occurring physical factors, as well as those produced by various types of devices used in prophylaxis and diagnostics. The basis of the therapeutic effect of physical factors on the human body is the ability of tissues to respond to stimuli. Conduction of physical stimuli to the body is possible by means of the skin, and more specifically its rich blood supply, innervation and numerous receptors. Most physical treatments have thermal effects. The effect of heat on the body is not always uniform and depends on the proper functioning of the thermoregulation system, the treated body surface, the intensity and duration of the stimulus, as well as the physical environment [43, 44]. In the presented studies, due to the usage of the thermal imaging method, a different reaction to the effects of short-wave diathermy was observed. The significance of the skin during physical procedures is confirmed by the statistically significant difference in changes in body temperature on the anterior and posterior sides of the knee joint. The difference results from the thickness of the skin, its innervation and the depth of blood vessels. On the front side of the knee, the skin is thicker, less innervated, less supplied with blood, the bone structure is quite shallow beneath it, and the tendons are poorly vascularised and less responsive to temperature changes. The back side of the knee joint is where large blood vessels pass, there are also skin and fat folds, due to which, this area reacts more strongly to temperature changes.

Advances in science and technology contribute to the development of physical medicine and the broadening of knowledge in the field of physiology and pathophysiology, thus enabling a more complete understanding of the mechanisms of interaction of physical factors and the possibilities of their use in prevention and therapy [45]. Owing to the use of the thermovision method for assessing changes in the surface temperature of the body, we can show the body's reaction to the stimulus applied [5-9, 16-19, 25-27]. The short wave diathermy treatment was performed on the front side of the knee joint, whilst the thermal reaction was recorded on the back side. This may prove the depth of penetration of therapeutic impulses. It is also information that the local treatment has a more general effect, all be it limited to the surface of the thermal impulse. This local effect can be observed by assessing the thermal changes observed on the left, untreated knee and hand. In both these cases, the temperature differences were not greater than in the tests performed at the stage of evaluating the functionality of the thermoregulatory system.

In the literature on the subject, there are no studies determining the body's response to a single short-wave diathermy 
treatment. In their research, Gruszka et al. [3] showed that the thermal imaging method can be used in the case of treatments with extreme temperatures-systemic cryotherapy and volcanic stone massage. As in the case of short-wave diathermy, in the studies by Gruszka et al., changes in the thermal image allowed for the assessment of the effect of a single therapeutic treatment. From the changes observed in the physical procedure described in this paper, we can mention the widening of blood vessels, the image of which is erythema on the skin and an increase in the temperature of the treatment area. However, in the case of treatments with the use of volcanic stones, a peripheral reaction was also observed on the lower limbs, which may indicate the general effect of these treatments [3]. Similarly, as described by Chwałczyńska et al. in the case of reactions occurring in the CPT test, the changes were also observed on the hand not participating in the cold pressor test [1]. In both of these cases, the reaction was observed not only at the specific point of the stimulus action, but also in distant places, unlike short-wave diathermy treatment. Knowing the body's reaction to a single treatment, it can be concluded how the series of such treatments will affect the body. The multiple widening of the lumen of the blood vessels improves the nutrition and oxygenation of the tissues in the treatment area, and thus has a positive effect on its functional state.

The research presented in this paper was carried out on a group with a properly functioning thermoregulation system. In order to assess the correct functioning of the thermoregulation system, CPT and IC tests based on blood parameters measurements were performed. So as to supplement them, thermal imaging tests were also performed by determining the average starting temperature for a given area. It was observed that there were no statistically significant differences in the body surface temperature between the various stages of the research experiment. This is important information as the studies were conducted simultaneously and the total duration was on average $60 \mathrm{~min}$. At that time, the body could cool down independently of the treatments used. The lack of statistically significant differences between the research stages excludes the influence of the duration and temperature in the test room on the subject. Comparing the temperature of the anterior and posterior surface of the right and left knee joints in the tests of the functional evaluation of the thermoregulatory system, it was observed that the temperature of the front side is on average $2.5{ }^{\circ} \mathrm{C}$ lower than the temperature of the back side, and in the case of short-wave diathermy treatment, the difference for the right knee joint (where the procedure was carried out) amounted to $3.5^{\circ} \mathrm{C}$ and for the left $2.5^{\circ} \mathrm{C}$. Assuming the difference between the anterior and posterior surfaces of the knee joint as $100 \%$, the temperature change recorded after the procedure was as much as $140 \%$. It proves the body's reaction to the applied stimulus.
Due to the intensity of the stimulus used in the therapy, the experiment should be repeated on other research groups in which the body's thermoregulation system may function incorrectly or otherwise. This applies especially to young and elderly people or people with additional comorbidities that may affect the thermoregulation system. In these people, physical treatments can cause different reactions. Assessment of the impact of a single physical procedure on the body is very important in the therapeutic process and can be applied to the treatment area, intensity and duration of the stimulus used. The use of the thermovision method to assess the effectiveness of the thermotherapy treatment will enable its use in people with impaired superficial sensation or abnormalities in the functioning of the thermoregulation system. Full use of the thermovision map of the human body requires further research not only on a group of healthy people but also with various disease entities.

The obtained results of the conducted research indicate the necessity to continue the research project. In the presented studies, the procedure was performed once on healthy, young people, in whom no thermal disturbances were found on the skin surface, therefore, in order to be able to draw final conclusions, the study should be repeated taking into account a greater number of procedures, also used in patients with medical indications for short-wave diathermy. Comparisons should also be made between the thermal reaction of a healthy person and the medical recommendations for physical treatments depending on various disease entities.

\section{Conclusions}

The thermovision method allows the assessment of changes in the body under the influence of a physical stimulus. It can be used to estimate the body's response to a stimulus in people with abnormalities in superficial sensation.

The short-wave diathermy treatment in people with a properly functioning thermoregulation system caused an increase in the surface temperature at the specific area of the treatment.

The recommendation to use a physical procedure should be preceded by an assessment of the functioning of the body's thermoregulation system. Reactions to the prescribed physical treatment may be different in people with a problematic autonomic system.

Acknowledgements To Phd Krzysztof Dudek, for his substantive help and valuable suggestions during the research and analysis of its results. To Phd Katarzyna Gruszka and MA Elżbieta Jackowska, for their help and support in the realisation of the scientific research. To Professor Tomasz Halski, for valuable comments and kind discussion. To the late Professor Ireneusz Całkosiński of the Medical University of Wrocław, 
for the scientific signposting, support, kindness, empathy and help provided during the implementation of scientific research.

Authors' contributions Conceptualization: BK, Krzysztof A Sobiech. Methodology: BK, ED-Włodarczyk, Krzysztof A Sobiech. Formal analysis and investigation: BK, AC. Writing-original draft preparation: BK, ED—Włodarczyk. Writing—review and editing: KAS, AC. Funding acquisition: BK. Resources: BK, AC. Supervision: KAS, AC.

Funding No funds, grants, or other support was received.

Availability of data and material (data transparency) The results of the studies presented are part of a large ongoing study that is not yet closed. They contain sensitive data, therefore they are not freely available.

\section{Declarations}

Conflicts of interest All authors certify that they have no affiliations with or involvement in any organization or entity with any financial interest or non-financial interest in the subject matter or materials discussed in this manuscript. The authors did not receive support from any organization for the submitted work.

Ethics approval The present study was carried out in accordance with the standards of the European Association of Thermology in the laboratory of the Physiotherapy Department at the University School of Physical Education in Wrocław. Prior permission number KB-446/2016 was obtained from the Bioethical Commission at Wrocław Medical University. In accordance with the Helsinki Declaration, the respondents gave their informed written consent to participate in the research experiment. The study was performed in accordance with the CONSORT statement (Consolidated Standards of Reporting Trials) and the CONSORT FLOW DIAGRAM scheme.

Open Access This article is licensed under a Creative Commons Attribution 4.0 International License, which permits use, sharing, adaptation, distribution and reproduction in any medium or format, as long as you give appropriate credit to the original author(s) and the source, provide a link to the Creative Commons licence, and indicate if changes were made. The images or other third party material in this article are included in the article's Creative Commons licence, unless indicated otherwise in a credit line to the material. If material is not included in the article's Creative Commons licence and your intended use is not permitted by statutory regulation or exceeds the permitted use, you will need to obtain permission directly from the copyright holder. To view a copy of this licence, visit http://creativecommons.org/licenses/by/4.0/.

\section{References}

1. Chwałczyńska A, Gruszka K, Całkosiński I, Sobiech K.A. Thermovision analysis changes of human surface temperature in cold pressor test. BioMed. Res. Int. 2015; 5.

2. Gruszka K, Chwałczyńska A, Bera N, Sobiech KA. Thermovision analysis of surface temperature in menopausal women after whole body cryostimulation. JPHNMR. 2014;3:51-8.

3. Gruszka K, Szczuka E, Całkosiński I, Sobiech KA, Chwałczyńska A. Thermovision analysis of surface body temperature changes after thermal stimulation treatments in healthy men. ABB. 2018;20(2):79-87.
4. Sobiech KA, Gruszka K, Chwałczyńska A, Jędrzejewski G. Application of thermovision to body surface temperature analysis of regular winter swimmers. PAK. 2014;60(12):1112-5.

5. Cholewka A, Stanek A, Klimas A, Sieroń A, Drzazga Z. Thermal imaging application in chronic venous disease: pilot study. J Therm Anal Calorim. 2014;115(1):1609-18. https://doi.org/10. 1007/s10973-013-3356-0.

6. Cholewka A, Kajewska J, Marek K, Sieroń-Słotny K, Stanek A. How to use thermal imaging in venous insufficiency?. J Therm Anal Calorim, 2017;130:1317-1326 https://doi.org/10.1007/ s10973-017-6141-7.

7. Cholewka A, Stanek A, Klimas A, Sieroń A, Drzazga Z. Thermal imaging application in chronic venous disease - pilot study. J Therm Anal Calorim. 2014;115(1):1609-18.

8. Cholewka A, Stanek A, Wójcik M, et al. Does local cryotherapy improve thermal diagnosis similar to whole-body cryotherapy in spinal diseases? J Therm Anal Calorim. 2017;127:1155-62. https://doi.org/10.1007/s10973-016-5453-3.

9. Ptaszyński P, Kaczmarek K, Wranicz J. Autonomic nervous system assessment in cardiology. Post Nauk Med. 2014;7:439-46.

10. Amruta K, Amrutkuvar P, Trupti W, Khushboo B. Effect of ground level reverse treadmill walking versus incline reverse treadmill walking as an adjunct to conventional physiotherapy in chronic knee osteoarthritis subjects. Ind J Pub Health Res Develop. 2019;10(4):12-8.

11. Boyaci A, Tutoglu A, Boyaci N, Aridici R, Koca I. Comparison of the efficacy of ketoprofen phonophoresis, ultrasound, and short-wave diathermy in knee osteoarthritis. Rheumatol Int. 2013;33(11):2811-8.

12. Incebiyik S, Boyaci A, Tutoglu A. Short-term effectiveness of short-wave diathermy treatment on pain, clinical symptoms, and hand function in patients with mild or moderate idiopathic carpal tunnel syndrome. J Back Musculoskelet Rehabil. 2015;28(2):221-8.

13. Laufer Y, Dar G. Effectiveness of thermal and athermal shortwave diathermy for the management of knee osteoarthritis: a systematic review and meta-analysis. Osteoarthritis Cartilage. 2012;20(9):957-66.

14. Łukowicz M, Weber-Rajek M, Ciechowska- Mendyk K, Zalewski $\mathrm{P}$, Ziętek K. Comparison of the effectiveness of local cryotherapy and pulsed short-wave diathermy combined with kinesitherapy in treatment of gonarthrosis symptoms. Acta Bio-Opt Inform Med. 2011;17(1):28-33.

15. Przedborska A, Pomorska E, Świątczak M, Staniszewska M, Misztal M, Raczkowski JW. Application of high frequency currents in treatment of patients with knee osteoarthritis. Fizjoter Pol. 2018;18(4):112-21.

16. Cholewka A, Drzazga Z, Sieroń A, Stanek A, Knefel G, Kawecki M, Nowak M. Some applications of thermal imaging in medicine. In: Z. Drzazga, K. Ślosarek editors. Some aspects of medical physics - in vivo and in vitro studies, Monographs of Polish Journal of Environmental Studies, 2010.

17. Englisz-Jurgielewicz B, Cholewa A, Ziółkowska K, Kasprzyk T, Kawecki M, Glik J, Nowak M, Sieroń K, Stanek A. Thermal imaging in burns diagnostics. Inżynier i Fizyk Medyczny. 2020;1(9):63-5 (in Polish).

18. Kasprzyk-Kucewicz T, Cholewka A, Englisz-Jurgielewicz B, Mucha R, Relich M, Kawecki M, Sieroń K, Onak P, Stanek A. Thermal Effects of Topical Hyperbaric Oxygen Therapy in Hardto-Heal Wounds-A Pilot Study. Int J Environ Res Public Health. 2021;18:6737. https://doi.org/10.3390/ijerph18136737.

19. Soffer AD, Tabacco N, Geffin R, Young E, Caine M, Hardiga PC, Wright DDI. Thermal imaging of superficial leg circulation improves venous diagnostic efficiency and completeness. Vascular Disease Management. 2020;17(11):E208-11. 
20. Vardasca R, Magalhaes C, Silva P, Abreu P, Mendes J, Restivo MT. Biomedical musculoskeletal applications of infrared thermal imaging on arm and forearm: A systematic review. J Therm Biol. 2019;82:164-77.

21. Gulsen M, Pekyavas NO, Atici E, Sahin FN, Guler O. Effects of kinesio taping on postural stability in young soccer players. Acta Medica Mediterranea. 2019;35:169-74.

22. Boerner E, Bauer J, Kuczkowska M, Podbielska H, Ratajczak B. Comparison of the skin surface temperature on the front of the thigh after application of combined red-IR radiation and diadynamic currents executed in a different sequence. J Therm Anal Calorim. 2015;120(1):921-8.

23. Choi E, Lee PB, Nahm FS. Interexaminer reliability of infrared thermography for the diagnosis of complex regional pain syndrome. Skin Res Technol. 2013;19(2):189-93.

24. Chudecka M, Lubkowska A. The use of thermal imaging to evaluate body temperature changes in athletes during training and a study on the impact of physiological and morphological factors on skin temperature. Hum Mov. 2012;13(1):33-9.

25. Bauer J, Grabarek M, Migasiewicz A, et al. Non-contact thermal imaging as potential tool for personalized diagnosis and prevention of cellulite. J Therm Anal Calorim. 2018;133:571-8. https:// doi.org/10.1007/s10973-018-7232-9.

26. De Weck AL, Gluck U, Derer T. Thermographic analysis of allergic reactions in the skin. Allergy Clin Immun News. 1990;2:7-10.

27. Pisula-Lewandowska A, Ratajczak B, Skrzek A, Dębiec-Bąk A, Demidaś A. Therapy monitoring with the use of various physical procedures. In: Podbielska H, Skrzek A, editors. Biomedical applications of thermal imaging. Publishing House of Wrocław University of Technology; 2014. p. 135-45.

28. Baic A, Kasprzyk T, Rżany M, Stanek A, Sieroń K, Suszyński K, et al. Can we use thermal imaging to evaluate the effects of carpal tunnel syndrome surgical decompression? Medicine 2017; 96(39), e7982.

29. Gruszka K, Jędrzejewski G, Sobiech K, Chwałczyńska A. Body surface temperature adaptations after ice-cold water immersion in regular winter swimmers. Biol Exercise. 2018;14(1):87-101.

30. Kasprzyk T, Cholewka A, Mleczko B, Stanek A, Sieroń K. The applications of active dynamic thermography in tissue - like system - searching for medical applications. Inżynier i Fizyk Medyczny. 2018;7(4):251-4.

31. Moreira DG, Costello JT, Brito CJ, Adamczyk JDG, Ammer $\mathrm{K}$, Bach AJE, et al. Thermographic imaging in sports and exercise medicine: A Delphi study and consensus statement on the measurement of human skin temperature. J Therm Biol. 2017;69:155-62.

32. Rusowicz A, Piwnik J. Thermal research loaded hip joint. ABiD. 2016;1:49-53.

33. Tykalski A, Filipiak KJ, Januszewicz A, Litwin M, Narkiewicz K, Prejbisz A, et al. Principles of management of arterial hypertension-2019 Guidelines of the Polish Society of Hypertension. PTNT, Hypertension in Practice. 2019;5(1):1-86 (in Polish).

34. Chwałczyńska A. Fat-Fat Free age-related index as a new tool for body mass assessment Studies and Monographs of the University School of Physical Education in Wrocław, Wrocław, 2017, 124 (in Polish).

35. Hines EA, Brown GE. Cold pressor test for measuring blood pressure reaction: Data concerning 571 normal and hypertensive subjects. Am Heart J. 1936;11:1-9.

36. Magiera A, Kaczmarczyk K, Wiszomirska I. The diagnostic value of the Crampton test (the orthostatic test) in the elderly individuals. Adv Rehabil. 2011;3:29-34.

37. Mishra S, Manjareeka M, Mishra J. Blood pressure response to cold water immersion test. Int J Biol Pharm Al Sci. 2012;10:1483-91.

38. Ritesh M, Karia MD, Mahavirsingh Rajput MD, Hemant B, Mehta D, Pradnya A, Gokhale MD. Blood pressure response to cold pressor test in normal young healthy subjects, a prediction of future possibilities of hypertension. J Phys Pharm Adv. 2012;2:223-6.

39. Shaw BH, Garland EM, Black BK, Paranjape SY, Shibao CA, Okamoto LE, et al. Optimal diagnostic thresholds for diagnosis of orthostatic hypotension with a 'sit-to-stand test.' J Hypertens. 2017;35(5):1019-25.

40. Kaźmierska B. Thermal imaging evaluation of temperature changes in the area of knee joints in volunteers subjected to selected energetic physical treatments. PUM Szczecin, doctoral thesis, 2019 (in Polish).

41. Ammer K. The Glamorgan protocol for recording and evaluation of thermal images of the human body. Thermol Int. 2008;18:125-9.

42. Ring EFJ, Ammer K. The technique of thermal imaging in medicine. Thermol Int. 2000;10:7-14.

43. Boerner E, Bauer J, Ratajczak B, Dereń E, Podbielska H. Application of thermovision for analysis of superficial temperature distribution changes after physiotherapy. J Therm Anal Calorim. 2015;120(1):261-7.

44. Rudzińska A, Witkoś J, Nowotny J. The local and remote changes of skin temperature after certain physical treatment. Fizjoterapia. 2004;12(4):27-37.

45. Lahiri BB, Bagavathiappan S, Jayakumar T, Philip J. Medical applications of infrared thermography: A review. Infrared Phys Technol. 2012;55(4):221-35.

Publisher's Note Springer Nature remains neutral with regard to jurisdictional claims in published maps and institutional affiliations. 